Revista Mídia e Cotidiano

Artigo Seção Livre

Volume 12, Número 1, abril de 2018

Submetido em: 09/04/2018

Aprovado em: 15/04/2018

\title{
COMUNICAÇÃO, TECNOLOGIA E TERRITÓRIO NO METRÔ DE SÃO PAULO ${ }^{1}$
}

COMMUNICATION, TECHNOLOGY, AND TERRITORY IN THE SÃO PAULO

$S U B W A Y$

Janice CAIAFA ${ }^{2}$

\section{Resumo:}

Os circuitos comunicacionais de um metrô são conjuntos híbridos de interfaces maquínicas e humanas, constituindo um ambiente midiático onde mensagens, imagens, agentes e passageiros circulam. Tenho explorado, em pesquisa etnográfica, como esses circuitos se reconfiguram com a automatização integral da condução (trens sem piloto humano) no cotidiano das viagens na Linha 4 do metrô de São Paulo (a primeira linha totalmente automática da América Latina) e nas ressonâncias produzidas na rede. Neste texto examino os desdobramentos dessa reconfiguração no longo corredor de transferência entre as Linhas 2 e 4, lugar sensível superpovoado de artefatos técnicos e de passageiros. Exploro como, no contexto das dinâmicas da transferência nesse local, se constroem formas de comunicação e de território e como são atualizadas as propriedades de rede do metrô.

Palavras-chave: Processos comunicativos; Tecnologia; Território; Metrô (São Paulo); Etnografia.

\begin{abstract}
:
Subway communicative circuits are hybrid arrangements of machinic and human interfaces, shaping a media environment where messages, images, agents, and riders circulate. I have been exploring, relying on ethnographic work, how those circuits get reconfigured with the introduction of fully automated trains (whose operation is unmanned) in the daily rides of Line 4 of the São Paulo subway (the first fully automated line of Latin America), and in the resonances produced in the whole network. In this text, I investigate the developments of this reconfiguration in the long transfer corridor between Lines 2 and 4, sensitive site overcrowded with both artifacts and riders. I explore how, in the context of the dynamics of subway transfer in that site, forms of communication and territory are shaped, and how Subway network properties are actualized.
\end{abstract}

Keywords: Communicative Processes; Technology; Territory; Subway (São Paulo), Ethnography.

\footnotetext{
${ }^{1}$ Uma versão inicial deste trabalho foi apresentada no $7^{\circ}$ Simpósio Nacional de Ciência, Tecnologia e Sociedade (ESOCITE.BR), Brasília, 2017, GT Sociotécnica e Cultura Contemporânea.

${ }^{2}$ Doutora em Antropologia pela Universidade de Cornell, EUA, e Professora Titular da Escola de Comunicação da UFRJ. Poeta e pesquisadora do CNPq.
} 


\section{A LINHA E A REDE}

Este texto apresenta alguns resultados de uma pesquisa etnográfica sobre a experiência de automatização integral da condução no metrô de São Paulo ${ }^{3} \mathrm{Nessa}$ modalidade de condução dos trens, não há piloto humano. $\mathrm{O}$ equipamento embarcado conduz o trem sob a supervisão de uma sala central de controle. A Linha 4-Amarela, recentemente inaugurada em maio de 2010, é a primeira linha totalmente automática da América Latina. Tenho examinado as dinâmicas das transformações sociotécnicas no cotidiano das viagens na rede metroviária paulista impulsionada pela introdução dessa inovação tecnológica.

Os dados produzidos são resultado de uma convivência que venho cultivando com meus interlocutores - profissionais da Companhia do Metropolitano de São Paulo e da ViaQuatro, concessionária que opera a linha automática, e usuários desse serviço — , da observação participante nas instalações do metrô e da análise de documentos relativos sobretudo à implementação da Linha 4.

A automatização da operação é um processo que vem avançando nos metrôs do mundo e sua figura mais expressiva é, sem dúvida, a automatização integral da condução. De fato, muitas linhas metroviárias são, atualmente, em grande parte, automáticas. Com os sistemas de ajuda à condução, introduzidos já nos anos 1970, o equipamento embarcado pode conduzir o trem, cabendo ao condutor abrir e fechar as portas e, em alguns casos, dar a partida. Trata-se da modalidade de condução denominada "Piloto Automático" ou ATO (Automatic Train Operation). É o caso das outras linhas do metrô de São Paulo e das Linhas 1 e 4 do metrô do Rio de Janeiro, por exemplo.

Nos anos 1980 foi construído o primeiro metrô com condução totalmente automática, o VAL da cidade de Lille, França. O VAL é um metrô leve, ou seja, atende uma demanda moderada e tem baixa capacidade de carregamento — um sistema, portanto, em que o processo de automatização é em geral menos complexo. Na década de 1990 e no novo milênio, foram realizadas as primeiras experiências de automatização integral da condução em metrôs pesados, que são sistemas de alta capacidade. Exemplos seriam as Linhas 1 e 14 do metrô de Paris, a Linha D do metrô de Lyon e a Linha 4-

\footnotetext{
${ }^{3}$ Trata-se de pesquisa em curso que tem o apoio do CNPq.
} 
Amarela do metrô de São Paulo. As modalidades Driverless Train Operation (DTO) e Unattended Train Operation (UTO) representam os níveis mais avançados de automação. ${ }^{4}$ A condução é integralmente automática, com o equipamento embarcado conduzindo o trem sob a supervisão do Centro de Controle Operacional ${ }^{5}$. Na modalidade DTO conserva-se um agente no trem e, na UTO, opera-se sem presença humana a bordo. A Linha 4-Amarela foi preparada para operar no nível UTO, sem auxílio humano.

É importante notar que a implementação da Linha 4 não trouxe apenas a inovação tecnológica, esta já bastante expressiva. O projeto envolveu também a concessão da linha ao setor privado para operação no âmbito do primeiro contrato de Parceria Público Privada do país. Assinado em 2006, o contrato entrega a operação e a manutenção da linha à empresa ViaQuatro por 30 anos. A Companhia do Metropolitano de São Paulo continua operando as outras linhas e se encarrega da expansão do sistema.

A inovação tecnológica carreou também mudanças na gestão humana. Ocorreu uma reorganização do trabalho dos metroviários em que as funções básicas de operação, manutenção e segurança se justapõem em alguns casos. Fenômeno frequentemente presente nas experiências de automatização integral da condução nos metrôs (CAIAFA, 2014, 2015, 2016; JOSEPH, 2004; VILLOUTREIX, 1990), estas mudanças também estão relacionadas com imperativos da administração privada e critérios de produtividade.

A Linha 4 inaugurou-se, portanto, com um conjunto de novidades que a particularizam no contexto da rede. De diversas maneiras, os próprios usuários percebem algumas diferenças, muitas vezes assinalando, à sua maneira, questões pertinentes de operação e administração. Assim, no âmbito dessa particularização que não só a tecnologia, mas a própria mudança no regime de apropriação da linha contribui para construir, um problema novo se coloca, segundo venho observando na pesquisa: o das formas de ligação da nova linha com a rede.

Em trabalho anterior (CAIAFA, 2016), já me propus a explorar esse problema da linha e da rede, tentando mostrar como tem assomado na experiência cotidiana de

\footnotetext{
${ }^{4}$ Para mais detalhes sobre os diferentes níveis de automação cf. Alouche (1990).

${ }^{5} \mathrm{O}$ CCO é um centro de comando a distância, onde técnicos ocupam consoles ou postos de trabalho — que consistem em computadores e comunicadores de vários tipos — sob o comando de um supervisor. Grandes painéis de controle ótico exibem imagens de todo o sistema e gráficos operacionais.
} 


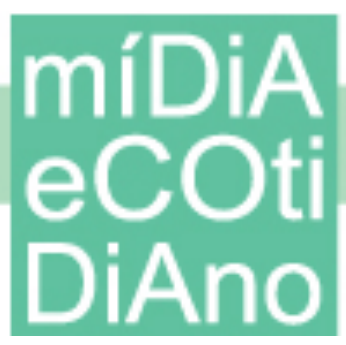

usuários e de profissionais encarregados da operação. Neste texto, atenho-me a um aspecto pontual dessa problemática, examinando as dinâmicas sociais e as características operacionais do corredor de transferência entre a Linha 4-Amarela e a Linha 2-Verde que se faz pela Estação Paulista, na Amarela e, na Verde, pela Estação Consolação.

Logo no início da pesquisa fui atraída pela aventura de caminhar naquele corredor. Em seguida, usuários com quem conversava o mencionavam espontaneamente como digno de nota em sua experiência de viajar na Linha 4 especificamente e no metrô. Meus interlocutores profissionais também costumam destacá-lo como um lugar particularmente sensível do sistema. Trata-se de imenso corredor, repleto de etapas e maquinismos, além dos transeuntes, que, em horários de pico, podem constituir multidões.

Assinale-se também que essa transferência é crucial no contexto da rede, pois interliga uma linha que percorre o centro de São Paulo, a Linha 2-Verde, e outra, 4Amarela, que serve o núcleo financeiro e cultural da cidade. Trazendo conversas com profissionais da concessionária e do Metrô, ${ }^{6}$ com usuários, além de minha experiência como passageira, exploro aqui questões de território, comunicação e sociabilidade no espaço da transferência Paulista/Consolação ${ }^{7}$.

Numa rede metroviária as linhas se conectam por princípio e a organização das transferências entre elas é fundamental para permitir a circulação e constituir, em suma, a própria rede. Inclusive, a Linha 4 foi concebida desde o projeto original, como me mostraram meus interlocutores e apontam vários documentos, como linha integradora. É interessante examinar, portanto, como hoje ela vem exercendo essa sua função na rede paulista no contexto das mudanças aportadas por sua implementação no ambiente sociotécnico do metrô.

A análise dessas dinâmicas no corredor de transferência entre as duas linhas é precedida, aqui neste texto, por um breve desenvolvimento de perspectivas que venho tentando construir na pesquisa - o metrô como ambiente maquínico, como meio de

\footnotetext{
6 "Metrô" será como doravante vou me referir à Companhia do Metropolitano de São Paulo neste texto, tal como em geral fazem meus interlocutores.

${ }^{7}$ Gostaria de agradecer, entre meus interlocutores, especialmente a Caetano Jannini, Manuel Xavier Lemos Filho, Jorge Secall, Mauricio Dimitrov, João Emmanoel, Wagner Fajardo, Bruna Spezia Melo, Bel Estrela e Zé Roberto Valente.
} 
comunicação e como rede -, importantes para introduzir as afirmações que farei em seguida.

O metrô de São Paulo possui atualmente 5 linhas em operação: 1-Azul, 2-Verde, 3-Vermelha, 4-Amarela e 5-Lilás, totalizando 75 estações. Transporta cerca de 4,7 milhões de passageiros diariamente. ${ }^{8}$ Numa das maiores aglomerações do mundo — mais de 11 milhões de habitantes ${ }^{9}$-, a mobilidade se coloca como problema central. Além disso, a orientação para o carro, característica também da cidade, torna particularmente importante o apoio ao transporte coletivo e, neste ponto, o metrô trouxe transformações muito positivas. Não só por gerar acesso, mas por ter exercido, desde a sua inauguração, a função crucial de organização do transporte coletivo na cidade - como me indicaram meus interlocutores - , aportando inclusive a ideia de integração entre modais.

Vê-se como a problemática da linha e da rede se torna particularmente pertinente e como é interessante evocá-la no contexto de tantas mudanças no metrô de São Paulo.

\section{O METRô COMO AMBIENTE MAQuínico, COMO MEIO DE COMUNICAÇÃO E COMO REDE}

Em trabalhos anteriores desenvolvi a noção de ambiente maquínico (CAIAFA, 2013 ; 2015) para caracterizar a centralidade do componente tecnológico no meio social do metrô. Nos metrôs, seus utilizadores — usuários e operadores - - abordam constantemente os mais diversos maquinismos e povoam com eles o espaço construído. "Maquínico", conceito de Deleuze e Guattari (1980), se refere diretamente à máquina técnica e, no mesmo gesto, alude às dinâmicas sociais pois, para os autores, estas se resolvem em arranjos que se encontram em regime de máquina ou em estado de conexão. A dupla referência nos interessa neste estudo das múltiplas interfaces técnicas e humanas que se produzem no ambiente do metrô. Latour (1992: 254) mostra como tem sido inútil considerar a "sociedade" ou "a tecnologia" ("two ghosts") apartadas em duas extremidades, mesmo que estas venham a se alcançar ou, adventiciamente, a se combinar. Seria preciso conceber uma "gradação" que se percorre em nome de "um programa de ação" onde são produzidas constantes transformações entre o técnico e o humano.

\footnotetext{
${ }^{8}$ Cf. http://www.metro.sp.gov.br/metro/institucional/quem-somos/index.aspx. Acesso em 31/03/2018.

${ }^{9}$ Cf. www.cidades.ibge.gov.br. Acesso em 31/03/2018.
} 
A experiência da automatização integral da condução na Linha 4 - como costuma acontecer nesses casos - se fez acompanhar da introdução de outros automatismos no edifício do metrô. São, por exemplo, as portas automáticas nos bloqueios e torniquetes e as portas de plataforma, que abrem e fecham com as do trem e têm uma função importante de segurança, sobretudo quanto se trata de trens automáticos. As máquinas estão mais presentes ao mesmo tempo que a agência humana é reconfigurada, sendo um exemplo especialmente loquaz o próprio desaparecimento do condutor. O componente tecnológico do ambiente maquínico é enfatizado.

O metrô é também um meio no sentido de medium, meio de comunicação. Morley (2011) argumenta a favor de que "comunicação" possa expressar tanto a circulação de mensagens quanto a de pessoas e mercadorias. Ora, um metrô funciona precisamente através da circulação e imbricação singular de fluxos materiais e semióticos. Para que o metrô funcione, é preciso que mensagens sejam constantemente deflagradas: do Centro de Controle Operacional para os equipamentos de estação e embarcados que se comunicam com o CCO e entre si. Relatórios são constantemente emitidos pelo CCO e as mensagens não cessam para garantir o movimento dos trens e o funcionamento de todos os equipamentos elétricos e eletrônicos do ambiente do metrô.

É assim que o metrô realiza seu objetivo precípuo: conduzir pessoas. Estas, por sua vez, circulam pelo espaço do metrô e, em alguma medida, abordam as máquinas como fazem, por sua vez, os agentes e supervisores em campo ou nas salas técnicas para poder viajar. Os usuários do metrô se encontram, ainda, em situação de comunicação face a face entre si e com os agentes que trabalham na linha.

Os circuitos comunicacionais de um metrô são conjuntos híbridos de interfaces maquínicas e humanas. Tenho explorado como esses circuitos se reconfiguram no contexto da automatização na Linha 4 e nas ressonâncias produzidas na rede. A ênfase no componente tecnológico do ambiente maquínico gera novas interfaces e tanto a operação quanto as próprias viagens se assentam sobre uma nova distribuição das agências humana e maquínica.

Um metrô é também uma rede, como me sugeriram meus interlocutores, sobretudo os profissionais do Metrô. Como mostra Dupuy $(1987,1991)$ - a partir do texto de Raffestin e numa discussão sobre infraestruturas urbanas - uma rede é definida 
antes de tudo pela propriedade de "conexão" (connexité), que diz respeito a "se os pontos são ou não ligados à rede" (DUPUY, 1987, p. 181). Qualidade básica, é quase uma condição para que as outras se realizem. Outro aspecto, que decorre dessa qualidade básica, é a "conectividade" (connectivité), que consiste na existência de um máximo de relações diretas e alternativas entre os pontos.

Observemos também que considerar o metrô como meio de comunicação e ambiente maquínico, como temos feito, é também uma forma de concebê-lo como rede. Dupuy aponta que há um "desejo de relação" (ou, poderíamos dizer, de comunicação) na imaginação da rede, que é um desejo ao mesmo tempo individual e coletivo — desejo, afinal, de seus usuários, atuais ou potenciais. É preciso que o metrô funcione como meio de comunicação num ambiente complexo de máquinas e humanos para que a rede se realize e seja possível viajar.

Examinando a concretização das qualidades reticulares, Dupuy distingue "rede técnica" de "rede territorial". O desejo de territorialidade e comunicação precisa ser incorporado à rede técnica pelos operadores para que ela se torne uma rede territorial. As características reticulares ou territoriais não estão garantidas, mas precisam ser conquistadas. A rede técnica realiza apenas em alguma medida a rede territorial, pois há sempre constrangimentos não só de ordem técnica, mas também econômicos e políticos.

Ao explorar as dinâmicas da transferência no corredor entre as Linhas 2 e 4, examino como se apresentam ali as propriedades reticulares - nesse lugar em que a Linha 4-Amarela, portadora de tantas mudanças no contexto do metrô, tenta alcançar uma outra linha, integrando-se ao conjunto do metrô. Fazer a transferência, percorrendo esse corredor, é uma das maneiras de realizar, para os usuários, o desejo individual e coletivo de comunicação, vivenciando o metrô como rede.

\section{LONGA TRAVESSIA E CORRIDA DE OBSTÁCULOS}

O corredor de transferência Paulista/Consolação é longuíssimo e frequentemente superpovoado, sendo que em horários de pico, como já mencionei, a aglomeração é enorme. ${ }^{10}$ Na multidão cerrada mesmo, quase não é possível se mover mas, nos momentos

\footnotetext{
${ }^{10}$ Nos muitos documentos que tenho colecionado não encontrei dados sobre dimensão e população do local e tampouco nos sites das duas empresas. Recorri a matérias de imprensa e, após uma seleção baseada num cálculo de verossimilhança, elegi os seguintes. O corredor de transferência tem 195 metros de comprimento e 8 metros de largura.
} 
em que se pode, quando há espaço livre, há muitos transeuntes que vão em disparada. Outra característica da travessia nesse espaço é uma espécie de diversidade de ambientes ou de etapas que é preciso atravessar.

Caminhando na Estação Consolação, deve-se pegar a passagem que conduz à transferência para a Linha 4-Amarela. Em seguida, anda-se mais um pouco e se alcança um caminho com esteiras rolantes, um longo túnel cujo final não se consegue avistar. As paredes são abauladas e há canos coloridos aparentes na parte superior. Estes ocorrem, a propósito, em várias outras áreas da linha e são bonitos adornos, embora nesse corredor de transferência ajudem a fechar o espaço. São três esteiras paralelas. Dependendo do fluxo de passantes em cada direção, duas serão ligadas para a ida e a terceira para a volta ou vice-versa. Há também espaço de chão para quem prefere caminhar sem ajuda.

Aprendi também que as esteiras podem ser desligadas nos horários de pico para evitar que as pessoas caiam com o movimento na intensa aglomeração. Quando há espaço, em horários mais livres, quem quer correr escolhe em geral a parte fora das esteiras. Ali se corre de verdade. Há quem corra nas esteiras também, mas se vai esbarrando naqueles que se colocam à direita sem se moverem ou que se movem em ritmo mais lento, o que retarda a corrida.

Sempre em frente, chega-se a mais um conjunto de três esteiras que, como as outras, cobrem uma grande extensão. Entre os dois conjuntos de esteiras há pequenos pilares que marcam o espaço, orientando a direção do fluxo humano. Ao longo de todo o caminho, divisórias (pequenos cilindros e faixas) funcionam também como direcionadores de fluxo, permitindo a passagem e, como ocorre nos metrôs em geral, ao mesmo tempo impedindo que se passe.

Trata-se de espaço bem mapeado e delimitado, regulado, como se diz na linguagem dos metrôs. ${ }^{11}$ Naquele corredor fechado e regulado para a marcha sempre em frente, a diversidade e a profusão de elementos visuais contribuem para compor um espaço muito povoado e preenchido pelo artefato técnico.

Disponível em: https://noticias.uol.com.br/ultimas-noticias/agencia-estado/2013/01/12/mp-investiga-tunel-do-metroapos-11-feridos-em-tumulto.htm, acesso em 09 abr. 2018. Cada esteira tem 46 metros: http://www1.folha.uol.com.br/cotidiano/2013/09/1336742-pane-em-esteira-rolante-fere-20-em-metro-de-sp.shtml. Em 2013 passavam pelo corredor $236 \mathrm{mil}$ pessoas diariamente: http://g1.globo.com/sao-paulo/noticia/2013/09/metrodiz-que-ligacao-entre-paulista-e-consolacao-nao-atingiu-superlotacao.html.

${ }^{11}$ Para uma análise da questão da regulação nos metrôs, $c f$. CAIAFA (2013). 
Em seguida, chega-se ao sopé de escadas rolantes direcionadas para baixo, pois a Linha 4-Amarela fica num patamar mais profundo. Naquele ponto vemos o grande portão que separa as duas linhas e que, durante o horário de operação comercial, permanece aberto. Chegamos ao limite entre as duas que é, em alguma medida, o limite entre a Linha 4 e o resto do metrô. O portão já aponta para isso. Os agentes se postam em cada lado, separados em ambientes contíguos. Os uniformes mostram também a divisão, distinguindo-os: preto para os agentes do Metrô e cinza azulado para os da ViaQuatro.

Em meu caderno de campo há muitas referências à experiência de atravessar esse corredor. Numa ocasião, escrevi:

\begin{abstract}
Era por volta das duas da tarde. Na transferência Consolação/Paulista muitos corriam, tanto na esteira quanto na parte central de chão duro. A impressão que se tem é que, diante de uma extensão tão grande, as pessoas se arremessam para, literalmente, vencer a distância - ganhar da distância, batê-la, chegando logo. Há também um clima de huis clos nesse espaço subterrâneo e cheio de etapas marcadas pela presença de certos tipos de maquinismo (esteira, escada rolante), com direções estipuladas que é preciso seguir. A grande extensão, o aspecto de compartimento fechado e a variedade de gestos ao longo de caminhos determinados fazem do percurso uma espécie de corrida de obstáculos. Ali se pode experimentar a aglomeração de desconhecidos característica das cidades, a princípio sem nada em comum salvo o objetivo de chegar do outro lado. Mas havia também alguns poucos que ficavam parados nas esteiras à direita, como eu.
\end{abstract}

Vários usuários comentaram, em conversa comigo, sobre como experimentam a travessia no corredor de transferência Paulista/Consolação. Carolina, usuária frequente das duas linhas, observa que costuma evitar passar por lá:

E aí, se você não tá nesse ritmo, aquilo já te coloca num estado de... agitação e de... Você também fica desse jeito, né? E quando você não tá correndo e você tá... parece que você entra nessa vibração, assim. Então, se eu não tô precisando correr, eu prefiro manter o meu estado mais tranquilo e evitar.

Muitas vezes, me contou, ela sai à rua e caminha até a estação da outra linha, preferindo pagar outra passagem.

Há outros lugares no metrô em que se corre muito ou onde há muita aglomeração e, em geral, é difícil transitar, particularmente em transferências? Eu própria já observei que sim, e ouvi a confirmação de usuários, mas parece que as condições nesse corredor de transferência são especiais. A Linha 3-Vermelha, que faz a ligação Leste-Oeste, é a mais carregada do sistema. Muitos usuários a citam ao se referirem à questão da superlotação, tema que costumam trazer com frequência e espontaneamente às conversas A transferência em Sé, entre a Linha Vermelha e a Linha Verde, como muitos 


\section{míDiA

comentaram, é particularmente carregada. Gabriel observa que ali não se consegue correr por falta de espaço. Outro tipo de corrida, para pegar lugar no trem quando as portas se abrem, por exemplo, não parece ser um fenômeno da Linha 4-Amarela em particular, mas sim da 3-Vermelha. Renato, que mora na Zona Leste e utiliza a Linha Vermelha, diz que na Estação Brás e na Tatuapé costuma haver muito empurra-empurra nessa hora.

O metrô de São Paulo está entre os mais carregados do mundo e é frequente a experiência de multidão em seus espaços. No trabalho de campo, este é um aspecto marcante e, por vezes, um problema que se precisa enfrentar.

De toda forma, no corredor de transferência entre a Linha 4-Amarela e a 2-Verde, tanto a corrida quanto a aglomeração se realizam com grande intensidade e com características particulares, como têm apontado meus interlocutores e eu própria constatado em muitas ocasiões.

Atualmente a Linha 4-Amarela compreende nove estações: Butantã, Pinheiros, Faria Lima, Fradique Coutinho, Oscar Freire, Paulista, Higienópolis-Mackenzie, República e Luz. A conclusão da segunda fase de implementação da linha acrescentará mais duas. Em maio de 2014, a linha transportou 785 mil passageiros por dia (DE PAULA et al, 2015, p. 24). Da Linha 4 é possível fazer transferência para as linhas 1-Azul, 2Verde e 3-Vermelha, e ainda para as linhas ferroviárias 7-Rubi, 9-Esmeralda e 11-Coral.

A transferência em Pinheiros para a Linha 9-Esmeralda da CPTM (Companhia Paulista de Trens Metropolitanos) é igualmente muito interessante e particularmente importante, pois é a Linha Esmeralda, ferroviária, que realiza hoje a conexão da Linha 5Lilás, metroviária, com a rede de metrô. Para fazer a transferência, os usuários que vêm da ferrovia sobem até uma estrutura elevada que conduz ao acesso da Linha 4. Avista-se todo o entorno pelas paredes transparentes nessa passarela que é como um túnel a céu aberto. Como constatei e comentam alguns usuários, há correria ali também, mas nada que se compare ao que se passa na transferência Paulista/Consolação. O percurso é longo, mas as condições são mais aprazíveis, com a intensa paisagem urbana em torno. Parece mais improvável que haja o desejo de se livrar do ambiente e o imperativo de chegar. No corredor para a Linha Verde, há os aspectos de espaço fechado, como observei acima, e de marcha muito direcionada pelos artefatos técnicos, diferentemente do que se passa em Pinheiros. 
Várias vezes observei usuários se entregando a correria desenfreada em outros espaços gigantescos, embora não em grande número. A movimentação nas estações da Linha 4-Amarela envolve percorrer vários mezaninos pois, como mencionei, a linha foi escavada fundo no solo. Nesses percursos, creio, as pessoas podem ser tomadas pela mesma urgência que ocorre no corredor para Linha Verde diante da extensão colossal que é preciso cobrir, frequentemente em meio a uma multidão. Contudo, também aqui nos mezaninos os aspectos de fechamento e direção obrigatória não são tão enfatizados quanto no corredor de transferência Paulista/Consolação.

Respondendo à minha pergunta sobre se acha que essa corrida tão intensa a que ele espontaneamente se referiu seria um fenômeno só dessa transferência, afirmou Renato:

Só na transferência, só ali. Da Linha Verde. Ali você tem que...Tem uns corredores, tem umas esteiras, parará. Eu não sei por quê, o pessoal corre, corre... Mas não é correr de andar rápido só, não...

Perguntei se observava isso nas duas direções, ida e volta:

Ida e volta. Corre, corre, corre, parece maratona. De dar cotovelada, com coisa na mão...

\section{TRANSIÇÕES}

Há um conjunto de fatores que parece produzir essa situação. Foucault (2001), ao analisar as formas de conceber o espaço ao longo da história, indica que o espaço moderno se constitui por posicionamentos (emplacements), em contraste com o espaço medieval, hierarquizado e encaixado em oposições (espaço de colocações), e com o espaço do Renascimento que, com Galileu, se abre ao infinito (extensão). Na modernidade, um conjunto de relações define cada tipo específico de posicionamento e a análise deveria justamente buscar essas relações em cada caso. No corredor da transferência Paulista/Consolação, essas relações se estabelecem entre os passantes, entre eles e o aparato técnico ali implantado, ou seja, com os componentes do espaço construído e, ainda, com os agentes que se posicionam para disciplinar o trajeto, operando por sua vez os dispositivos técnicos sob o comando do CCO.

Essas relações são provavelmente variáveis, mas previsíveis se examinamos as condições oferecidas e impostas nesse percurso. Já descrevemos, de forma preliminar, estas condições: a enorme extensão, a presença de dispositivos facilitadores mas também 
disciplinadores (esteiras, escadas, orientadores de fluxos, delimitadores de espaço), a situação de huis clos (marcha sempre em frente num compartimento fechado sob a terra).

Tudo isso cria um modo de passar: as pessoas frequentemente correm se podem (se a aglomeração não for cerrada) e, assim, as relações entre elas tendem a envolver esbarrar, ultrapassar e até empurrar; na relação com os artefatos, alguns aceitam a ajuda das esteiras, por exemplo, mas outros só querem ultrapassá-las, chegar antes delas ao tentar cobrir o mais rápido possível aquele percurso, seja usando as próprias esteiras ou correndo nos espaços de chão. Quanto aos artefatos técnicos, há registros de problemas de funcionamento - o suficiente, inclusive, para a imprensa local noticiar. No dia 4 de setembro de 2013, por exemplo, uma esteira travou, fazendo com que pessoas caíssem. Os cilindros de orientação de fluxo desabaram, houve correria e vinte passageiros ficaram feridos. ${ }^{12}$ Um interlocutor meu, que trabalha na Comissão de Monitoramento e Controle das Concessões e Permissões (CMCP), órgão que acompanha e fiscaliza esses contratos no Estado de São Paulo, apontou, sem ser solicitado por mim, essa transferência como problemática e por isso muito monitorada pelo Metrô e pela ViaQuatro, caracterizando-a como lugar onde ocorrem muitos acidentes, causados pelo humano ou pela máquina.

Se utilizarmos uma das categorias que Foucault (2001) aponta em sua análise dos posicionamentos modernos, podemos dizer que, no corredor de transferência, se trata de "posicionamentos de passagem", ao mesmo tempo assinalando que as relações definidoras desses posicionamentos não cessam de produzir também obstrução. No corredor que se encarrega de ligar os pontos à rede, ocorre uma forma de marcar ou estriar o espaço que trabalha contra a circulação - e, portanto, em última instância, contra o metrô como rede, como ambiente e como meio de comunicação.

Explorei as características das transferências num metrô concebendo-as como regiões "liminares" (CAIAFA, 2013), no sentido de Gennep (1978) e Turner (2009). As sociedades produzem constantemente lugares que se interpõem entre outros e que apresentam, por isso, aspectos híbridos ou indefinidos. Os portais, as soleiras, os limites entre países, cidades, ou mesmo certas circunscrições dentro de cidades, são regiões liminares. As transferências funcionam como zonas de transição, são pórticos por onde

${ }^{12}$ Cf. http://sao-paulo.estadao.com.br/noticias/geral,tumulto-na-linha-4-do-metro-deixa-20-feridos,1071228. Acesso em $1^{\circ}$ de fevereiro de 2017. 


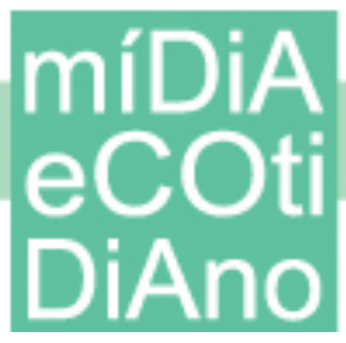

se alcançam outras linhas numa rede de metrô. O passageiro, ao transferir, salta para outros itinerários - realizando seu desejo de circulação e de comunicação na rede. Esse salto oblíquo (CAIAFA, 2013) leva a novos circuitos e misturam-se mais os viajantes, mais heterogeneidade se produz no ambiente do metrô. Para essa realização de desejo e produção de heterogeneidade, a circulação deveria ser o mais fluida possível nas regiões de transição para franquear a passagem. As transferências marcam limiares entre linhas na rede e são grandes guardiões de suas qualidades de conexão e conectividade.

O aspecto "passage" (GENNEP, 2009) que caracteriza certos lugares ocorre de forma generalizada nas sociedades conhecidas, se apresentando fortemente ritualizado nas sociedades tradicionais. Em sua obra pioneira, Gennep descreve inúmeras ocorrências dos "ritos de passagem" - por exemplo, os ritos de puberdade ou de iniciação em religiões ou em sociedades secretas - classificando-os e, no limite, afirmando o ritual como um princípio da vida em sociedade. DaMatta (1978, p. 12) observa que Gennep “insinua tomar a própria vida social na sua dialética entre rotinas e cerimoniais, repetições e inaugurações, homens e mulheres, velhos e moços, nascimentos e mortes etc. como um ritual". Gennep (1978, p. 41) escreve que toda sociedade "pode ser considerada como uma espécie de casa dividida em quartos e corredores". Estamos constantemente cruzando esses aposentos e passando para alcançar algum outro na casa. No rito de passagem, numa primeira fase nos separamos de um lugar na estrutura social (separação) para em seguida nos colocarmos num espaço e num tempo de transição (fase liminar) e, finalmente, nos integrarmos num novo lugar (fase de agregação). Mesmo que não seja no contexto de um rito tão codificado, não cessaríamos de transitar ao longo dessas situações.

É extraordinário como um metrô - rede, ambiente maquínico, meio de comunicação - atualiza, à sua maneira, a passagem ritual ou, retomando o texto de Foucault (2001), os posicionamentos de passagem. O desejo de relação, na formulação de Dupuy $(1987,1991)$ que mencionamos acima, ou de comunicação, como podemos preferir, determina que possamos alcançar a outra margem, que passemos e nos agreguemos constantemente aos diversos lugares do metrô até chegar a nosso destino. Circulação desimpedida na rede, ligação máxima entre pontos é o desejo do viajante. Não é difícil submeter esta aposta ao teste empírico e confirmá-la. Nos estudos que tenho realizado sobre alguns metrôs do mundo, não cesso de constatar que os usuários desse 


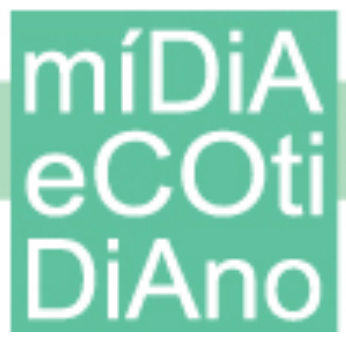

equipamento coletivo de transporte querem antes de tudo poder chegar ao maior número de pontos possível com facilidade, presteza e a preços acessíveis. Falam disso todo o tempo. As transferências são elementos chave na rede para a realização desse desejo. Elas são duplamente "passagem" por serem elas próprias ambientes singulares ao se colocarem entre linhas numa rede de transporte e por funcionarem como soleiras entre essas linhas para permitir que se as alcance, e prossiga a viagem.

$\mathrm{Na}$ transferência Paulista/Consolação, o rito de passagem se estende quase indefinidamente numa espécie de longa fase liminar. Os que disparam parecem querer apressar o processo, vencendo a todo custo a distância, batendo-a na corrida que envolve tantos obstáculos e que se dá num ambiente fortemente delimitado - com várias etapas, disciplinadores de fluxo, máquinas diversas e a companhia de outros humanos, usuários e agentes, que podem ser tomados, sobretudo nos momentos de grande multidão, como obstáculos também. $\mathrm{O}$ aspecto de compartimento fechado caracteriza igualmente essa marcha sempre para frente no longo percurso que o passageiro precisa realizar.

$\mathrm{Na}$ aglomeração muito cerrada não é possível correr. Em horário de pico de demanda, uma multidão enorme se concentra no corredor. Como temos visto, as características particulares desse corredor e as relações que se estabelecem envolvendo humanos, máquinas e espaço construído geram passagem ao mesmo tempo que obstrução. Tanto o fenômeno da corrida quanto o passo a passo na multidão são característicos do corredor de transferência Paulista/Consolação e resultam de imperativos desse ambiente especial no metrô de São Paulo. Por outro lado, enquanto figurar numa multidão que caminha lentamente releva exclusivamente de uma imposição dos operadores no contexto das determinações do espaço construído, correr repousa numa decisão do transeunte ao mesmo tempo que decorre também desses imperativos, e contribui, por sua vez, para produzir formas de comunicação e sociabilidade nesse ambiente.

\section{UM TERRITÓRIO DE FRONTEIRAS}

O corredor de transferência entre as Linhas Amarela e Verde se caracteriza por uma forma particular de marcar o espaço envolvendo o próprio espaço construído, os artefatos técnicos e os atores humanos. Trabalham nessa marcação as esteiras, escadas, 


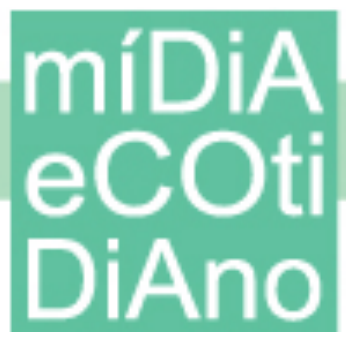

orientadores de fluxo, separadores dos domínios de cada linha e a própria extensão do lugar, que delimita também ao referir o espaço a um limite perdido além da visão e contribui, assim, para fechar o corredor.

Quanto aos humanos, participam à sua maneira dessa forma de estriar ou marcar o espaço, mesmo que disciplinados pelo ambiente técnico imposto tanto pelo projeto construtivo quanto por decisões operacionais. Entre os usuários, invariavelmente numerosos, vários ou muitos se entregam à conhecida corrida para chegar ao fim do túnel — impondo aqui, claramente, um modo de passar que marca igualmente aquele espaço — e, em alguns momentos, constituem multidão. Os agentes colocam-se em geral junto às marcações de limites, como entre os conjuntos de esteiras ou diante das escadas rolantes, ou ainda junto aos divisores ou orientadores de fluxo ao longo das esteiras. Além de, certamente, estarem ali para auxiliar os usuários e permitir o fluxo, também se ocupam de estabelecer limites, ou seja, de disciplinar a circulação e assim contribuir, junto com os artefatos técnicos, para essa forma de marcar o espaço. Com seus uniformes diferenciados, do Metrô e da concessionária, e seu posicionamento em cada lado da fronteira, atuam para delimitar também a divisão de domínios.

Numa ocasião conversei com um agente na parte entre o segundo conjunto de esteiras e as escadas rolantes, ou seja, bem na fronteira entre as linhas. Eu tinha autorização para pesquisar na Linha 4 e não em outras linhas, e ele me alertou, então, que "para lá” já era "o Metrô". A princípio me surpreendi porque para mim tudo era o metrô. Até entender que ele se referia à Companhia do Metrô. Explorei outras menções a essa separação e constatei que uma linguagem confusa pode por vezes se produzir (CAIAFA, 2016). Naquele momento o agente, que foi, aliás, bem gentil comigo em nossa conversa, me chamava a atenção para uma questão importante que dizia respeito às autorizações para pesquisa e, ao mesmo tempo, definia os limites de jurisdição, poder $e$ responsabilidade das duas empresas. Não só os artefatos, mas a presença de dois grupos distintos de agentes - sob o comando, cada um deles, de um CCO e sob diferentes administrações - contribui para produzir uma demarcação ao mesmo tempo física, operacional, simbólica e política do espaço.

Todas estas características que encontramos no corredor de transferência Paulista/Consolação, envolvendo espaço construído, artefatos e agentes, mas também os 
próprios usuários - mesmo que antes de tudo estejam submetidos aos constrangimentos impostos pelos outros componentes —, tendem a introduzir uma retenção ou uma obstrução naquele lugar de passagem.

Mencionei acima que um interlocutor profissional caracterizou o corredor como um lugar preocupante, cheio de acidentes e, por isso, muito monitorado. Eu mesma pude observar as imagens do local nos painéis da sala técnica onde conversávamos. Um outro interlocutor, ligado ao Sindicato dos Metroviários, falando sobre o corredor, me disse que era monitorado também para que se vigiassem os próprios agentes. Ele acredita que os operadores da Linha 4-Amarela tentam evitar o contato de seus empregados com os outros do Metrô. Com a concessão sobreveio, de fato, um outro regime de trabalho, organizado por outros princípios, como observei acima. Embora alguns trabalhadores experientes, entre agentes, supervisores e mesmo diretores, tenham sido absorvidos pela concessionária, formou-se, segundo aprendi, um contingente novo na linha automática e privatizada. Eles são representados pelo Sindicato dos Empregados nas Empresas Concessionárias de Rodovias e Estradas em Geral do Estado de São Paulo, e não pelo Sindicato dos Metroviários, reconhecido por todos com quem falei, e mesmo fora do meio, como sindicato forte. Meu interlocutor acha que há toda uma preocupação em evitar contágio.

Outros discordarão, inclusive, um supervisor do CCO da concessionária, que me relatou que a comunicação ali é total. Em qualquer caso, vemos a presença de dois corpos distintos de agentes que, mesmo que não possamos no momento decidir seu grau de interação ou separação e as possíveis consequências operacionais, são, ao menos, uma ponta que emerge de uma separação de fato e mais profunda na rede: duas administrações diferentes, dois regimes de trabalho, diferentes sindicatos, dois centros de comando operacional distintos, além da particularização da linha que a própria automatização aportou. Não é possível duvidar que haja comunicação suficiente entre as contrapartes no quotidiano operacional do metrô, do contrário a rede se inviabilizaria, o que não ocorreu. Mas é igualmente plausível levantar que essa separação no interior da rede produza seus efeitos.

Nesse corredor de transferência, que atua, precisamente, como condutor para que se realize a conexão da linha particularizada - tanto pela automatização quanto pela 
privatização - à rede, a fricção causada por essas novidades, sobretudo a mudança no regime de apropriação desse equipamento coletivo de serviço, pode ser, em alguma medida, também atuante, adicionando-se às outras tensões ali presentes.

Um engenheiro independente com quem conversei se mostrou preocupado com essa divisão no contexto da rede, citando-a como uma fonte potencial (e, como esta pesquisa foi esclarecendo, por vezes efetiva) de problemas de interface. Mostrei em outro trabalho (CAIAFA, 2016) como na própria construção das estações, a cargo do Metrô no âmbito da PPP, a modalidade de contrato (chamada turn-key), em que cabia ao consórcio de construtoras determinar os fornecedores, resultou numa diversidade de procedências dos artefatos técnicos que ocasionou problemas de comunicação entre eles no contexto do complexo sistema de automatismos. Outro aspecto que já criou desacordos, aparentemente solucionados, foi o fato de que os trens fornecidos pela concessionária deveriam se comunicar com as portas de plataforma construídas pelo Metrô e ocorria, por vezes, incompatibilidade técnica. Nas interfaces humanas, abria-se a brecha para ambas as partes fugirem à responsabilidade.

Por outro lado, a rede está em funcionamento - junto com as novas complicações e mesmo com as antigas, como a superlotação. Mas os acontecimentos nesse espaço sensível de conexão da linha à rede são dignos de atenção e emergem, acredito, no bojo dessa reconfiguração dos circuitos comunicativos no contexto da automatização e da privatização, embora não se expliquem só por aí.

Os problemas de conexão no corredor de transferência não se colocam com a mesma intensidade para a Linha 2-Verde, plenamente integrada. É antes de tudo a nova linha, com tantas novidades e particularidades, que é constantemente posta à prova quanto a seu maior ou menor sucesso em ligar-se ao conjunto — condição para que a rede técnica realize em grande medida a rede territorial, ou seja, para que se satisfaça o desejo individual e coletivo de conexão.

As tensões que emergem no corredor decorrem de um estriamento do espaço que prioriza a divisão de territórios, seja para disciplinar o fluxo num lugar inadequado para servir de passagem, seja para delimitar domínios. Seguindo Dupuy e Raffestin, podemos dizer que ali se dá uma "produção de território" antes de "área" do que de "rede". Na rede, a questão, como vimos, é a conexão entre os pontos e as ligações tanto mais diretas 


\section{míDiA

e múltiplas quanto possível. Na territorialidade de área, a questão é "limitar o espaço", escreve Dupuy, "para exprimir áreas de exercício de poder" (DUPUY, 1991, p. 56).

Por todos os fatores ali operantes, que tentamos mostrar aqui, produz-se no corredor de transferência Paulista/Consolação uma territorialidade em que a fronteira e a vizinhança predominam em vários momentos sobre a circulação e a conexão, figuras da rede. A circulação no corredor, de que depende a conexão com a outra linha e com o conjunto, é afetada pelo imperativo de marcar dividindo: por aqui esteira, mas sempre em frente e em fila, de novo esteira, por aqui não se pode ir, aqui somos nós e ali são eles. Essa produção de território antes de área do que de rede coloca problemas de comunicação nesse pórtico de transferência, tanto entre as interfaces humanas e técnicas ali atuantes quanto, em última instância, entre a linha e a rede - problemas que dizem respeito à própria concretização operacional e simbólica do metrô de São Paulo como rede.

O interlocutor com quem conversei na sala técnica e que levantou o problema dos acidentes e do monitoramento desse corredor, me relatou que havia um plano de construir um outro corredor embaixo do existente, em socorro do problema de superlotação. Esse outro túnel conduziria até uma nova saída, a ser construída, da Estação Paulista da Linha 4-Amarela (esta fica, de fato, na Rua da Consolação, ponto que não poderei explorar aqui). Isto porque se constatou que há usuários que utilizam o corredor de transferência não para trocar de linha, mas para chegar, a partir da Linha 4-Amarela, até o acesso da Linha 2-Verde e sair na Avenida Paulista. Alguns usuários interlocutores meus mencionaram o fato, um deles dizendo que ele próprio costuma fazer isso normalmente. Esse desvio de finalidade agrava a superlotação no corredor de transferência. Com a construção de uma via que, sob o corredor existente, conduzisse da Linha Amarela até uma saída na Avenida Paulista, esse agravante seria eliminado.

Mais recentemente, soube, através de outro interlocutor, que finalmente não se obteve autorização para a construção desse corredor, com que a concessionária havia se comprometido e que poderia talvez encaminhar alguns problemas daquele corredor.

No corredor de transferência Paulista/Consolação, uma forma particular de marcar o espaço - gerado pelas decisões operacionais, mas também pelo projeto 
construtivo e mesmo por um modo de passar atualizado pelos usuários — produz uma territorialidade antes de fronteira que de conexão, qualidade básica da rede. O sobreinvestimento na regulação (para disciplinar o fluxo e definir domínios) que ajuda a demarcar o espaço também contribui para o tipo de comunicação em que agentes, usuários e artefatos técnicos se engajam e que procurei descrever acima.

A implementação da Linha 4-Amarela, particularizada por todos os aspectos carreados pela inovação tecnológica e pelo novo regime de apropriação estipulado, trouxe interferências expressivas no metrô de São Paulo, notadamente em suas propriedades de rede. Isto se apresenta em alguma medida também na longa travessia nesse corredor de transferência.

\section{Referências}

ALOUCHE, Peter Ludwig. A tecnologia dos metrôs do mundo. Revista dos Transportes Públicos - ANTP, 1990, v. 12, n. 49, p. 43-51.

CAIAFA, Janice. Trilhos da cidade: viajar no metrô do Rio de Janeiro. Rio de Janeiro: Editora 7Letras, 2013.

—. Dinâmicas da experiência de automatização integral da condução no metrô de Paris. Contemporanea, v. 12, n. 03, set-dez 2014, p. 595-613. Disponível em:

http://www.portalseer.ufba.br/index.php/contemporaneaposcom/article/view/12288/9371

. Comunicação e sociabilidade no metrô de Paris: aspectos de um regime de interfaces. E-

Compós, v.18, n, 3, 2015, p.1-17. Disponível em:

http://www.compos.org.br/seer/index.php/e-compos/article/view/1241/867

O metrô de São Paulo e o problema da rede. Contemporanea, 2016, 14 (2).

DaMATTA, Roberto. Apresentação. In GENNEP, Arnold Van. Os Ritos de Passagem. Petrópolis: Vozes, 1978.

DE PAULA, Alan Santana et al. Parceria Público-Privada - Linha 4-Amarela - Expectativas e Resultados. $21^{\text {a }}$ Semana de Tecnologia Metroferroviária. AEAMESP, 2015.

DELEUZE, Gilles; GUATTARI, Félix. Mille Plateaux: capitalisme et schizophrénie. Paris: Les Éditions de Minuit, 1980.

DUPUY, Gabriel. Les réseaux techniques sont-ils des réseaux? Espace géographique. Tome 16, $\mathrm{n}^{\circ} 1987$, p. 175-184.

. L'urbanisme des réseaux. Théories et méthodes. Paris: Armand Colin, 1991.

FAYE, Jean Pierre. Introduction. Épicure. Doctrines et maximes. Paris: Hermann, éditeurs des sciences et des arts, 1990.

FOUCAULT, Michel. Des espaces autres. Dits et Écrits II, 1976-1988. Paris: Gallimard, 2001.

GENNEP, Arnold Van. Os Ritos de Passagem. Petrópolis: Vozes, 1978.

JOSEPH, Isaac. Météor: Les métamorphose du métro. Paris: Ed. Economia, 2004.

LATOUR, Bruno. Where Are the Missing Masses? The Sociology of a Few Mundane Artifacts. In BIJKER, Wiebe E.; LAW, John. (Orgs.), Shaping technology/building society: studies in sociotechnical change. Cambridge: The MIT Press, 1992, p. 225-258.

MORLEY, David. Communications and transport: The mobility of information, people and commodities. Media, Culture \& Society, v. 33, n. 5, 2011, p.743-759. 


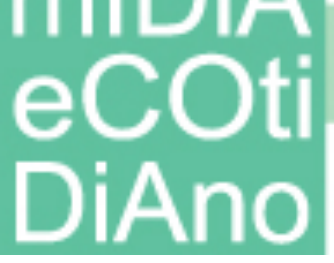

TURNER, Victor. The Ritual Process: Structure and Anti-Structure. New Brunswick and London: Aldine Transaction, 2009.

VILLOUTREIX, Frédéric. Modalités d'étude, de conception et d'introduction de systèmes intégrés d'automatismes. 339 f. Tese (Doutorado). École Nationale Supérieure des Mines de Paris, 1990. 